\section{Original Article}

Check for updates

\section{OPEN ACCESS}

Received: Feb 16, 2019

Revised: Mar 20, 2019

Accepted: Mar 26, 2019

Correspondence to

Mohammad Safarian

Department of Nutrition, Faculty of Medicine, Mashhad University of Medical Science, Azadi Square, Mashhad 91779-48564, Iran.

E-mail: safarianm@mums.ac.ir

Copyright (c) 2019. The Korean Society of Clinical Nutrition

This is an Open Access article distributed under the terms of the Creative Commons Attribution Non-Commercial License (https:// creativecommons.org/licenses/by-nc/4.0/) which permits unrestricted non-commercial use, distribution, and reproduction in any medium, provided the original work is properly cited.

\section{ORCID iDs}

Shabbou Ahmadi Bonakdar (D) https://orcid.org/0000-0003-4598-9361 Ahmad Reza Dorosty Motlagh (D) https://orcid.org/0000-0002-6937-7776 Mohammad Bagherniya (D) https://orcid.org/0000-0002-5861-6129 Golnaz Ranjbar (D)

https://orcid.org/0000-0003-0672-6323 Reza Daryabeygi-Khotbehsara (D) https://orcid.org/0000-0003-4064-978X Seyed Amir Reza Mohajeri (D)

https://orcid.org/0000-0002-6876-140X Mohammad Safarian (D)

https://orcid.org/0000-0003-2761-2747

Conflict of Interest

The authors declare that they have no competing interests.

\title{
Pre-pregnancy Body Mass Index and Maternal Nutrition in Relation to Infant Birth Size
}

\author{
Shabbou Ahmadi Bonakdar $\left(\mathbb{D},{ }^{1}\right.$ Ahmad Reza Dorosty Motlagh $\mathbb{1}^{\circ}{ }^{2}$ \\ Mohammad Bagherniya $\left(\mathbb{D},{ }^{3}\right.$ Golnaz Ranjbar $\left(\mathbb{D},{ }^{1}\right.$ Reza Daryabeygi-Khotbehsara $\left(\mathbb{D},{ }^{4}\right.$ \\ Seyed Amir Reza Mohajeri (1),' Mohammad Safarian (1) 1,5
}

'Department of Nutrition, Faculty of Medicine, Mashhad University of Medical Sciences, Mashhad, Iran ${ }^{2}$ Department of Community Nutrition, School of Nutritional Sciences and Dietetics, Tehran University of Medical Sciences, Tehran, Iran

${ }^{3}$ Department of Community Nutrition, School of Nutrition and Food Science, Food Security Research Center, Isfahan University of Medical Sciences, Isfahan, Iran

${ }^{4}$ Institute for Physical Activity and Nutrition (IPAN), School of Exercise and Nutrition Sciences, Deakin University, Victoria, Australia

${ }^{5}$ Metabolic Syndrome Research Center, Faculty of Medicine, Mashhad University of Medical Sciences, Mashhad, Iran

\section{ABSTRACT}

This cross-sectional study examined the relationship between maternal pre-pregnancy body mass index (BMI) and dietary intake on birth size in the north-east part of Iran. Maternal information including BMI and dietary intake from 453 healthy pregnant women were collected in 2013-2014. Maternal pre-pregnancy BMI were obtained from health records and dietary intakes in third trimester were collected by using a validated food frequency questionnaire (FFQ), which consisted of 160 Iranian foods. Anthropometric measurements of neonates including weight, height, and head circumference were $3.19 \pm 0.49 \mathrm{~kg}, 50.24 \pm$ $2.1 \mathrm{~cm}$, and $34.61 \pm 1.5 \mathrm{~cm}$, respectively. A significant difference was found in neonatal birth weight $(\mathrm{p}<0.001)$ and head circumference $(\mathrm{p}=0.002)$ between underweight and obese mothers. Furthermore, maternal intake of fat had a direct correlation with birth size. There was a positive relationship between vitamin A and potassium intake and birth height. The article concludes that normal maternal pre-pregnancy weight and appropriate diet are likely essential for healthy babies.

Keywords: Pregnancy; Birth weight; Body mass index; Diet; Neonate

\section{INTRODUCTION}

Accumulate evidence shows that the size at birth is associated with several chronic diseases such as obesity, cardiovascular disease, type 2 diabetes, hypertension in adults and the elderly [1-4]. Size at birth represent the fetus trajectory of growth that is highly affected by maternal nutrient intake [5]. The most important factors correlated with birth size are maternal anthropometric values and maternal dietary intakes. Parental levels of mental health status and economic circumstances are the other important factors which correlated with fetal growth [6]. 
Barker and colleagues [7] reported that the mother's adequate diet as well as health condition during pregnancy possess the long-term impacts on infant overall health even throughout adulthood. Maternal and undernourished children account for more than one third of all deaths among children [8].

Moreover, it has been reported that proper nutrition prior to and during pregnancy is of high importance for health outcomes in later life of both mothers and children [9]. In fact, it is proposed that to promote long term health of both mother and her child, following a healthy diet before and during pregnancy is crucial. In addition, the chance of entering life in good health increase in infants who are well nourished in the womb [10]. Hence, sufficient nutrients should be provided by mother's diet to meet infant's need without depleting in maternal nutrient stores [11,12]. It is believed that there is a close association between both low and high birth weight with increased infant mortality and long-term morbidity. Low birth weight is also associated with type 2 diabetes risk and ischemic heart diseases in the later life [13]. Moreover, mothers with body mass index (BMI) below 18.5 are expected to have underweight preterm infants $[14,15]$. It has been proposed that in developing nations, due to the existing several issues including socio-economic constraints, poor diet quality, high intensity of agricultural labour, and frequent reproductive cycles, the risk for malnutrition during pregnancy is high [16]. A recent review article indicated that nutrition status in pregnant women in developing countries is far from the desired level; as such, imbalanced macronutrients distribution, inadequate micronutrient consumption and predominantly plant-based diets was seen in most of the pregnant women in these countries [16]. It is suggested that the nutrition status of pregnant women in Iran has been poorly investigated [17]. It has been recently shown that food insecurity is prevalent in about $50 \%$ of Iranian households $[18,19]$. Importantly, the latest version of the National Integrated Micronutrient Survey of Iran conducted in 2012, shows that the nutritional status of Iranian pregnant women does not meet the recent recommendations and micronutrient insufficiency and deficiency are endemic in this population [20] suggesting that more studies, particularly longitudinal studies are needed. Data regarding the nutritional status and relationship between maternal nutrition and birth size of neonates of pregnant women in the east and north-east part of Iran is found to be insufficient. Nevertheless, in a previous study, it has been shown the prevalence of low birth weight in this area of the country was $11.1 \%$ [21].

Therefore, the aim of this study was to investigate the relationship between maternal dietary intake in the third trimester of pregnancy and BMI in first trimester pregnancy and birth sizebody's weight, length, and head circumference.

\section{MATERIALS AND METHODS}

This is a cross-sectional study and convening sampling technique has been used. A total of 560 pregnant women were recruited over 5 healthcare centers in Torbat-e Jam, Mashhad, Iran of which 500 women agreed to participate. The sample size was calculated based on a previous study [22], to provide $80 \%$ power at the 0.05 level of significance. Recruitment of subjects took place between May 2013 and December 2014. Ethics Committee of Mashhad University of Medical Sciences approved the study protocol. Moreover, written informed consent was obtained from all participants. The inclusion criteria included non-smoker women who were in their third trimester of pregnancy, aged between 18 and 40 years old, 
had no history of diabetes, cardiovascular diseases, and serious medical conditions, and gave birth at full-term. Women who left 70 items blank on the food frequency questionnaire (FFQ) and who reported a total daily energy intake outside the range of 800-4,200 kcal were excluded from the study. After these exclusions, 453 pregnant women remained for the present analysis, of which, BMI of 425 women were recorded in their health record.

\section{Data collection}

Demographic characteristics namely age, parity, and educational level were collected using a questionnaire. Income level was assessed by household assets ownership using an index of nine owned assets: house, car, washer dryers, liquid-crystal-display television, dishwasher, side by side refrigerator, rug, computer/laptop, and microwave [23,24]. Income status was categorized into three categories: high ( $7-9$ items), medium ( $4-6$ items), and low ( $\leq 3$ items) $[23,24]$. Face-to-face interview was conducted to obtain dietary intake in third trimester based on a valid and reliable FFQ consisting of 160 Iranian foods [25]. Maternal pre-pregnancy BMI were collected from health records. Maternal health records include the weight and height of the mother before pregnancy or the beginning of pregnancy. BMI was calculated as weight in kilograms divided by the square of height in meters $\left(\mathrm{kg} / \mathrm{m}^{2}\right)$.

In accordance with the BMI categorization proposed by World Health Organization (WHO), subjects were assigned into 4 groups [26]: underweight $(\mathrm{BMI}<18.5)$, normal $(18.5 \leq \mathrm{BMI}$ $\leq 24.9)$, overweight $(25 \leq \mathrm{BMI} \leq 29.9)$, and obese (BMI $\geq 30)$. Maternal dietary intake was assessed in third trimester. Pertained data on each infant (weight, length and head circumference at birth) was gathered from hospital records or health cards.

\section{Statistical analysis}

In this study, we collected mothers' BMI and their nutrient intakes including protein, carbohydrate, fat, fiber, potassium, folate, vitamin A, and vitamin E to investigate their relationship with weight, length and head circumference of newborn infants. First, descriptive statistics (mean \pm standard deviation) were used to describe the data. Then 3 regression models were fitted to investigate the relationship between birth outcomes and maternal nutrient intakes. In the first step, all the explanatory variables (mothers' BMI and their nutrient intakes) entered the regression model. Next, those variables with $\mathrm{p}$-value $>0.2$ were excluded and the final model was determined. In this paper, SPSS software version 16 (IBM Corp., Armonk, NY, USA) was applied for statistical analysis and significant level was 0.05 .

\section{RESULTS}

The mean age of pregnant women was $27 \pm 1.1$ years, $60 \%$ of whom expecting a second child.

As for educational level, $72 \%$ gained an undergraduate degree (42\% diploma and 30\% secondary school) while only a quarter obtained higher education. A total of 118 women were categorized in the low income level, 280 subjects were in the medium level and 55 women were categorized in high level of incomes. Among participants, 425 women were recorded BMI with WHO criteria; 36 mothers were underweight, 236 mothers were normal, 116 mothers were overweight, and 37 mothers were obese. Anthropometric measurements of neonates including weight, height, and head circumference were $3.19 \pm 0.49 \mathrm{~kg}, 50.24$ $\pm 2.1 \mathrm{~cm}$, and $34.61 \pm 1.5 \mathrm{~cm}$, respectively. Twenty-two infants were low birth weight (birth weight less than $2.5 \mathrm{~kg}$ ). The mean of energy and nutrient intake per day of women in the 
third trimester of pregnancy are presented in Table 1. In comparison to the dietary reference intakes (DRIs) [27], intake of carbohydrate and vitamin E was higher than DRI values in majority of pregnant women though women who consumed protein, fiber, vitamin A and folate less than DRIs value were higher than those who consumed these nutrients more than DRI values (Table 2).

\section{Relationship between birth weight, height, and head circumferences and} mother BMI

As shown in Table 3, at first we categorized pregnant women in 4 groups based on their BMI values; underweight, normal, overweight, obese pregnant women. In this regards, regression analysis has shown that birth weight and head circumference were significantly different between underweight and obese groups. The weight and head circumference were significantly lower in neonate whose mother was underweight in comparison to infants whose mother was obese (379.312 g [p < 0.001] and $1.065 \mathrm{~cm} \mathrm{[p=0.002],} \mathrm{respectively)} \mathrm{(Table} \mathrm{3).}$ However, birth height did not have a significant correlation with mothers' BMI.

\section{Relationship between birth weight, height, and head circumferences and mother macro and micro nutrients intake}

As presented in Table 3, mothers' fat intake has a significant positive association with infants' weight, head circumferences and height. Each gram of fat intake was associated with an increase of $3.92 \mathrm{~g}$ in mean weight of infant $(\mathrm{p}<0.001)$ as well as $0.013 \mathrm{~cm}$ in mean height $(\mathrm{p}=0.001)$ and $0.008 \mathrm{~cm}$ in mean head circumference of the neonate $(\mathrm{p}=0.006)$ (Table 3$)$. We also observed a positive relationship between vitamin A and potassium intake with birth height; for each $\mu \mathrm{g}$ maternal consumption of vitamin A and $1 \mathrm{~g}$ of potassium, birth height was increased by $10 \mu \mathrm{m}$ and $3 \mu \mathrm{m}$ ( $\mathrm{p}<0.05)$, respectively. However, maternal folate intake was not associated with birth size.

Table 1. Mean nutrient intake (per day) of women in the third trimester $(n=453)$

\begin{tabular}{lc}
\hline Nutrients & Mean \pm standard deviation \\
\hline Protein $(\mathrm{g})$ & $75.93 \pm 31.08$ \\
Fat $(\mathrm{g})$ & $81.76 \pm 36.53$ \\
Carbohydrate $(\mathrm{g})$ & $245.75 \pm 88.70$ \\
Fiber $(\mathrm{g})$ & $17.32 \pm 9.61$ \\
Energy $(\mathrm{kcal})$ & $2,021.53 \pm 741.67$ \\
Potassium $(\mathrm{g})$ & $2,917.87 \pm 1,355.72$ \\
Folate $(\mu \mathrm{g})$ & $412.85 \pm 320.90$ \\
Vitamin A $(\mu \mathrm{g})$ & $656.75 \pm 437.62$ \\
Vitamin E $(\mathrm{mg})$ & $8.77 \pm 15.64$ \\
\hline
\end{tabular}

Table 2. Distribution of pregnant women with intake less or more than DRIs (third trimester, $\mathrm{n}=453$ )

\begin{tabular}{lccc}
\hline Nutrient intake & DRIs & \multicolumn{2}{c}{ No (\%) } \\
\cline { 3 - 4 } & & $108(23.8)$ & $345(76.2)$ \\
\hline Carbohydrate $(g)$ & 175 & $245(54.1)$ & $208(45.9)$ \\
Protein $(\mathrm{g})$ & 71 & $398(87.9)$ & $55(12.1)$ \\
Fiber $(\mathrm{g})$ & 28 & $387(85.4)$ & $66(14.6)$ \\
Folate $(\mu \mathrm{g})$ & 600 & $325(71.7)$ & $128(28.3)$ \\
Vitamin A $(\mu \mathrm{g})$ & 770 & $58(12.8)$ & $395(87.2)$ \\
Vitamin E $(\mathrm{mg})$ & 15 & & \\
\hline
\end{tabular}

DRIs was not determined for energy and total fat.

DRI, dietary reference intake. 
Table 3. Relationship between anthropometric measures of newborns and pre-pregnancy BMI and nutrient intake of pregnant women

\begin{tabular}{|c|c|c|c|c|c|}
\hline Birth size parameters & Mother parameters ${ }^{*}$ & $\mathrm{~B}^{\dagger}$ & SEM & $\mathrm{t}^{\ddagger}$ & Sig. \\
\hline \multirow[t]{6}{*}{ Weight (g) } & Fat $(\mathrm{g})$ & 3.92 & 0.70 & 5.60 & 0.000 \\
\hline & Folate $(\mu \mathrm{g})$ & -0.07 & 0.07 & -0.98 & 0.329 \\
\hline & $\mathrm{BMI}<18.5\left(\mathrm{~kg} / \mathrm{m}^{2}\right)$ & -379.31 & 106.53 & -3.56 & 0.000 \\
\hline & $18.5 \leq \mathrm{BMI} \leq 24.9\left(\mathrm{~kg} / \mathrm{m}^{2}\right)$ & -71.16 & 80.39 & -0.88 & 0.377 \\
\hline & $25 \leq \mathrm{BMI} \leq 29.9\left(\mathrm{~kg} / \mathrm{m}^{2}\right)$ & -126.07 & 85.59 & -1.47 & 0.142 \\
\hline & $\mathrm{BMI} \geq 30\left(\mathrm{~kg} / \mathrm{m}^{2}\right)$ & $\mathrm{O}^{\dagger}$ & - & - & - \\
\hline \multirow[t]{6}{*}{ Head circumference $(\mathrm{cm})$} & Fat $(\mathrm{g})$ & 0.008 & 0.002 & 3.38 & 0.001 \\
\hline & Folate $(\mu \mathrm{g})$ & -0.0003 & 0.0002 & -1.43 & 0.153 \\
\hline & $\mathrm{BMI}<18.5\left(\mathrm{~kg} / \mathrm{m}^{2}\right)$ & -1.06 & 0.35 & -3.06 & 0.002 \\
\hline & $18.5 \leq \mathrm{BMI} \leq 24.9\left(\mathrm{~kg} / \mathrm{m}^{2}\right)$ & -0.34 & 0.26 & -1.31 & 0.191 \\
\hline & $25 \leq \mathrm{BMI} \leq 29.9\left(\mathrm{~kg} / \mathrm{m}^{2}\right)$ & -0.55 & 0.28 & -1.95 & 0.051 \\
\hline & $\mathrm{BMI} \geq 30\left(\mathrm{~kg} / \mathrm{m}^{2}\right)$ & $0^{\dagger}$ & - & - & - \\
\hline \multirow[t]{8}{*}{ Height $(\mathrm{cm})$} & Fat $(g)$ & 0.01 & 0.005 & 2.75 & 0.006 \\
\hline & Folate $(\mu g)$ & -0.0005 & 0.0004 & -1.29 & 0.196 \\
\hline & Vitamin A $(\mu g)$ & 0.001 & 0.0004 & 2.14 & 0.033 \\
\hline & Potassium (g) & 0.0003 & 0.0001 & 2.18 & 0.030 \\
\hline & $\mathrm{BMI}<18.5\left(\mathrm{~kg} / \mathrm{m}^{2}\right)$ & -0.30 & 0.48 & -0.62 & 0.532 \\
\hline & $18.5 \leq \mathrm{BMI} \leq 24.9\left(\mathrm{~kg} / \mathrm{m}^{2}\right)$ & 0.41 & 0.36 & 1.14 & 0.256 \\
\hline & $25 \leq \mathrm{BMI} \leq 29.9\left(\mathrm{~kg} / \mathrm{m}^{2}\right)$ & 0.22 & 0.39 & 0.57 & 0.569 \\
\hline & $\mathrm{BMI} \geq 30\left(\mathrm{~kg} / \mathrm{m}^{2}\right)$ & $\mathrm{O}^{\dagger}$ & - & - & - \\
\hline
\end{tabular}

All the explanatory variables (mothers' BMI and their nutrient intakes) entered the regression model. Next, those variables with $\mathrm{p}>0.2 \mathrm{were}$ excluded and the final model was determined.

BMI, body mass index; SEM, standard error of the mean.

${ }^{*}$ Mother's BMI status and macro and micro nutrients intake of the pregnant women; ${ }^{\dagger}$ Regression coefficient; ${ }^{\ddagger}$ Test statistic.

\section{DISCUSSION}

Findings of the present study show the association of maternal food intake and pre-pregnancy BMI on infant birth size; significant differences were found in neonatal birth weight and head circumference between underweight and obese mothers. In addition, no significant differences were found for neonatal birth size between normal and obese mothers. In this regard, a previous systematic review and meta-analysis has shown that being underweight pre-pregnancy is associated with increased risk of small for gestational age (SGA) and low birth weight and the risk of large for gestational age (LGA), whilst high birth weight and subsequent offspring overweight and obesity could increase in the mother who began pregnancy while overweight and obese [15]. However, it has been previously shown that the risk of an overweight and obese offspring increase in the mother who suffer from malnutrition during early gestation [15]. Moreover, in the present study, Mitanchez et al. [28] reported that infant birth weight is not different between normal and obese mothers, which is in line with our results. However, in another study, it was shown that higher maternal pre-pregnancy BMI is associated with higher birth weight, head circumferences, height [29]. This inconsistency could be due to a several potential factors and mechanisms such as maternal age, ethnicity, gestational hypertension, gestational diabetes mellitus, smoking during pregnancy, and gestational weight gain (GWG). For example, a previous study showed a significant and independent association between weight gain during pregnancy and birth weight for gestational age percentile [30]. Overall, it should be mentioned that differences in sample size, study method, quality grade of study, and source of pre-pregnancy BMI or infant birth weight, which all could affect the results of the studies are the other potential explanations for these heterogeneous findings [15]. In addition, the author believes that the association between maternal BMI and neonate head circumferences was poorly investigated suggesting more studies are required to clarify its precise association and involved underlying mechanisms. 
In the current study, no significant association between maternal pre-pregnancy BMI and neonatal birth length was observed. Although the results of a recent study conducted in China is line with our result [31], in their study, Thame et al. [32] showed that mothers with lower BMI were more likely to give birth to babies with lower birth height. It is proposed that birth height could be influenced by multiple factors, thus considering other factors such as race and maternal micronutrients intake (zinc, calcium, vitamin D) and parental height may explain the lack of association between maternal BMI and infants' birth height $[33,34]$.

Findings of the current study revealed a direct statistical significant association between maternal fat intake and infant birth size. The crucial role of fatty acids such as arachidonic acid and docosahexaenoic acid in fetal and infant growth and central nervous system development was earlier confirmed [35]. In this respect, a recent study found that intakes of fat were positively associated with neonate length [36]. Another study found that higher intakes of saturated fatty acids (SFAs) and omega-3 polyunsaturated fatty acids (n-3 PUFAs) in early stages of pregnancy were associated with increased birth weight and reduced incidence of SGA in a South Indian population [37]. In one study, a significant association was found between infant plasma cholesteryl ester arachidonic acid and infant birth weight and between triacylglycerol arachidonic acid and infant birth weight and length [35]. A study conducted in Japan showed that maternal intake of polyunsaturated fatty acids (PUFAs) has a marginal significance correlation with birth weight [38]. Intake of PUFAs was significantly positively associated with insulin-like growth factor (IGF-1) levels. Polyunsaturated fat intake may also affect the IGF-1 system. Umbilical cord IGF-1 is known as one of the major determinants of birth weight [39]. Similar patterns of the type of dietary fat with birth weight may indicate that fat intake affects birth weight [38].

In the current study, no association was observed between maternal folate intake and neonatal birth size. A study which was conducted among well-nourished Norwegian pregnant women indicated that dietary folate and plasma folate during the second trimester are not risk factors for infant birth size [40]. Nevertheless, a previous study revealed an association between folate intake and birth weight [41]. However, present study differs from others with respect to population characteristics, nutritional baseline status, amount of folate intake as well as timing and methods used to collect data.

In this study, a significant association was found between neonatal height and maternal vitamin A and potassium intake during the third trimester of gestation. In this respect most of the earlier studies have evaluated the association between maternal dietary intake and birth weight and little data is available to show the relationship between maternal dietary intake and birth height suggesting further investigation in longitudinal studies are required.

The limitation of the current study is that the maternal food intake was measured only once in the third trimester of pregnancy. It is better to examine the relationship between maternal food intake during all stages of pregnancy. Previous studies have shown that the effect of consuming different foods or nutrients on birth outcomes varies according to the stage of pregnancy [42]. With respect to linking GWG with birth weight, it is favorable to investigate GWG according to the guidelines of the Institute of Medicine (IOM) [29]. Furthermore, as mentioned earlier, this study was cross-sectional and like other cross-sectional studies, determining cause and effect is not possible. 


\section{CONCLUSION}

Our findings show that a pre-pregnancy BMI below 18.5 is associated with lower birth weight infants compared with obese mothers. Nutrition status of the mother might also influence the birth size of neonates. The association between maternal nutrition and pre-pregnancy BMI may have important implications for enhancing the nutritional health of mothers and babies.

\section{REFERENCES}

1. Eriksson J, Forsén T, Tuomilehto J, Osmond C, Barker D. Fetal and childhood growth and hypertension in adult life. Hypertension 2000;36:790-4. PUBMED | CROSSREF

2. Barker DJ, Osmond C, Simmonds SJ, Wield GA. The relation of small head circumference and thinness at birth to death from cardiovascular disease in adult life. BMJ 1993;306:422-6. PUBMED | CROSSREF

3. Eriksson J, Forsén T, Tuomilehto J, Osmond C, Barker D. Size at birth, childhood growth and obesity in adult life. Int J Obes Relat Metab Disord 2001;25:735-40. PUBMED | CROSSREF

4. Ong KK. Size at birth, postnatal growth and risk of obesity. Horm Res 2006;65 Suppl 3:65-9. PUBMED | CROSSREF

5. Borazjani F, Kulkarni SS, Ahmadi K. Impact of maternal factors on birth parameters in urban affluent pregnant women. Pak J Nutr 2011;10:325-7. CROSSREF

6. Muthayya S. Maternal nutrition \& low birth weight - what is really important? Indian J Med Res 2009;130:600-8. PUBMED

7. Barker DJ, Winter PD, Osmond C, Margetts B, Simmonds SJ. Weight in infancy and death from ischaemic heart disease. Lancet 1989;2:577-80. PUBMED | CROSSREF

8. Moghaddam Tabrizi F, Radfar F. A prospective study of hemoglobin status, micronutrient serum levels and nutrient intake of Iranian pregnant women during pregnancy and their relation to birth weight of the neonates. Proceedings of 2005 International Workshop on Thermal Investigation of ICs and Systems; 2005 Sep 27-30; Belgirate Lake Maggiore, Italy. Nice: EDA Publishing Association; 2014.

9. Singh M, Jain S, Choudhary M. Dietary adequacy of pregnant women of four district of Rajasthan. J Hum Ecol 2009;25:161-5. CROSSREF

10. Khoushabi F, Saraswathi G. Impact of nutritional status on birth weight of neonates in Zahedan City, Iran. Nutr Res Pract 2010;4:339-44. PUBMED | CROSSREF

11. Singh M, Jain S, Choudhary M. Dietary adequacy of pregnant women of four district of Rajasthan. J Hum Ecol 2009;25:161-5. CROSSREF

12. Landman JP, Hall JS. Dietary patterns and nutrition in pregnancy in Jamaica. J Trop Pediatr 1989;35:185-90. PUBMED | CROSSREF

13. Frederick IO, Williams MA, Sales AE, Martin DP, Killien M. Pre-pregnancy body mass index, gestational weight gain, and other maternal characteristics in relation to infant birth weight. Matern Child Health J 2008;12:557-67. PUBMED | CROSSREF

14. Han Z, Mulla S, Beyene J, Liao G, McDonald SD; Knowledge Synthesis Group. Maternal underweight and the risk of preterm birth and low birth weight: a systematic review and meta-analyses. Int J Epidemiol 2011;40:65-101. PUBMED | CROSSREF

15. Yu Z, Han S, Zhu J, Sun X, Ji C, Guo X. Pre-pregnancy body mass index in relation to infant birth weight and offspring overweight/obesity: a systematic review and meta-analysis. PLoS One 2013;8:e61627. PUBMED | CROSSREF 
16. Lee SE, Talegawkar SA, Merialdi M, Caulfield LE. Dietary intakes of women during pregnancy in low- and middle-income countries. Public Health Nutr 2013;16:1340-53.

PUBMED | CROSSREF

17. Esmaillzadeh A, Samareh S, Azadbakht L. Dietary patterns among pregnant women in the west-north of Iran. Pak J Biol Sci 2008;11:793-6.

PUBMED | CROSSREF

18. Daneshi-Maskooni M, Shab-Bidar S, Badri-Fariman M, Aubi E, Mohammadi Y, Jafarnejad S, Djafarian K. Questionnaire-based prevalence of food insecurity in Iran: a review article. Iran J Public Health 2017;46:1454-64. PUBMED

19. Mortazavi Z, Dorosty AR, Eshraghian MR, Ghaffari M, Ansari-Moghaddam A, Mohammadi M. Household food insecurity in Southeastern Iran: severity and related factors. Int J Food Sci 2017;2017:7536024. PUBMED | CROSSREF

20. Siassi F, Mohammad K, Djazayery A, Djalali M, Abdollahi Z, Dorosty AR, Pouraram H, Heshmat R, Khodaverdian K, Sotoudeh G, Yarparvar A. The National Integrated Micronutrient Survey 2012 (NIMS II). Tehran: Ministry of Health and Medical Education; 2015.

21. Davoudi N, Khezri M, Asgharpour M, Khatami SM, Hoseinpour M, Azarian AA. Prevalence and related factors of low birth weight in Mashhad, Iran. Iran J Neonatology 2012;3:69-76. CROSSREF

22. Ghavi AF, Niknami M, Kazemzadeh A. The relationship between maternal life styles during pregnancy and low birth weight at birth of term neonates. Iran J Obstet Gynecol Infertility 2012;15:14-24.

23. Daneshzad E, Yavari P, Rahimi-Foroshani A, Dorosty-Motlagha A, Nadjarzadeh A, Yavari L. Food insecurity, socio-economic status, and educational achievement: a cross-sectional study in high school girls, Noshahr, Iran. J Nutr Sci Diet 2015;1:141-8.

24. Shafi H, Dorosty Motlagh AR, Bagherniya M, Daeezadeh A, Safarian M. The association of household food insecurity and the risk of calcium oxalate stones. Urol J 2017;14:4094-5000. PUBMED

25. Nematy M, Nouri M, Ghazizahedi S, Norouzy A, Mohajeri SA, Shalaei N, Safariyan M, Esmaily H. Validity and reproducibility of Iranian food frequency questionnaire. Switz Res Park J 2013;102:2137-46.

26. Kaufman H, Jacques D, Coleman S, Ganzeier G. Prepregnancy body mass index and pregnancy outcome. Obstet Gynecol 2001;97:S71. CROSSREF

27. Trumbo P, Schlicker S, Yates AA, Poos M; Food and Nutrition Board of the Institute of Medicine; The National Academies. Dietary reference intakes for energy, carbohydrate, fiber, fat, fatty acids, cholesterol, protein and amino acids. J Am Diet Assoc 2002;102:1621-30.

PUBMED | CROSSREF

28. Mitanchez D, Jacqueminet S, Nizard J, Tanguy ML, Ciangura C, Lacorte JM, De Carne C, Foix L'Hélias L, Chavatte-Palmer P, Charles MA, Dommergues M. Effect of maternal obesity on birthweight and neonatal fat mass: a prospective clinical trial. PLoS One 2017;12:e0181307. PUBMED | CROSSREF

29. Kirchengast S, Hartmann B. Maternal prepregnancy weight status and pregnancy weight gain as major determinants for newborn weight and size. Ann Hum Biol 1998;25:17-28. PUBMED | CROSSREF

30. Margerison-Zilko CE, Shrimali BP, Eskenazi B, Lahiff M, Lindquist AR, Abrams BF. Trimester of maternal gestational weight gain and offspring body weight at birth and age five. Matern Child Health J 2012;16:1215-23. PUBMED | CROSSREF

31. Xiao L, Ding G, Vinturache A, Xu J, Ding Y, Guo J, Huang L, Yin X, Qiao J, Thureraja I, Ben X. Associations of maternal pre-pregnancy body mass index and gestational weight gain with birth outcomes in Shanghai, China. Sci Rep 2017;7:41073. PUBMED | CROSSREF

32. Thame M, Wilks RJ, McFarlane-Anderson N, Bennett FI, Forrester TE. Relationship between maternal nutritional status and infant's weight and body proportions at birth. Eur J Clin Nutr 1997;51:134-8. PUBMED | CROSSREF

33. Tawfeek H, Abdulla JN, Rasheed AH. Maternal dietary intake and pregnancy outcomes in Baghdad, Iraq. Food Nutr Bull 1999;20:179-82. CROSSREF 
34. An H, Yin S, Xu Q. Effects of supplementing calcium, iron and zinc on the fetus development and growth during pregnancy. Zhonghua Yu Fang Yi Xue Za Zhi 2001;35:370-3. PUBMED

35. Elias SL, Innis SM. Infant plasma trans, n-6, and n-3 fatty acids and conjugated linoleic acids are related to maternal plasma fatty acids, length of gestation, and birth weight and length. Am J Clin Nutr 2001;73:807-14. PUBMED | CROSSREF

36. Hjertholm KG, Iversen PO, Holmboe-Ottesen G, Mdala I, Munthali A, Maleta K, Shi Z, Ferguson E, Kamudoni P. Maternal dietary intake during pregnancy and its association to birth size in rural Malawi: a cross-sectional study. Matern Child Nutr 2018;14:e12433. PUBMED | CROSSREF

37. Mani I, Dwarkanath P, Thomas T, Thomas A, Kurpad AV. Maternal fat and fatty acid intake and birth outcomes in a South Indian population. Int J Epidemiol 2016;45:523-31. PUBMED | CROSSREF

38. Nagata C, Iwasa S, Shiraki M, Sahashi Y, Shimizu H. Association of maternal fat and alcohol intake with maternal and umbilical hormone levels and birth weight. Cancer Sci 2007;98:869-73. PUBMED | CROSSREF

39. Hawkes CP, Grimberg A. Measuring growth hormone and insulin-like growth factor-I in infants: what is normal? Pediatr Endocrinol Rev 2013;11:126-46. PUBMED

40. Nilsen RM, Vollset SE, Monsen AL, Ulvik A, Haugen M, Meltzer HM, Magnus P, Ueland PM. Infant birth size is not associated with maternal intake and status of folate during the second trimester in Norwegian pregnant women. J Nutr 2010;140:572-9. PUBMED | CROSSREF

41. Al-Shoshan AA. Diet history and birth weight relationship among Saudi pregnant women. Pak J Med Sci 2007;23:176-81.

42. Rao S, Yajnik CS, Kanade A, Fall CH, Margetts BM, Jackson AA, Shier R, Joshi S, Rege S, Lubree H, Desai B. Intake of micronutrient-rich foods in rural Indian mothers is associated with the size of their babies at birth: Pune Maternal Nutrition Study. J Nutr 2001;131:1217-24.

PUBMED | CROSSREF 